\section{Einladung zum RadiologieKongressRuhr 29. - 31.10.2015 in Bochum}
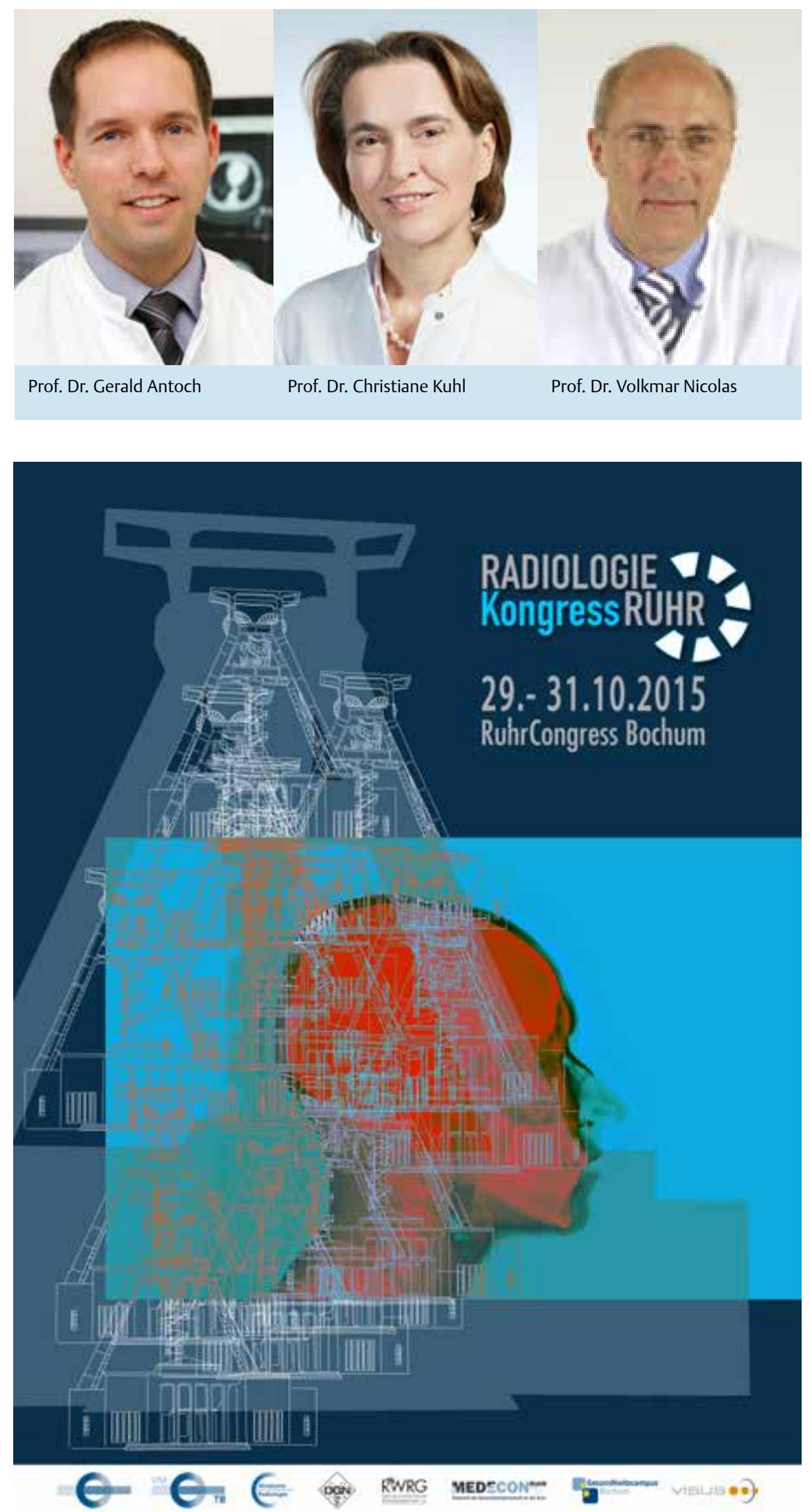

Liebe Kolleginnen und Kollegen,

der RadiologieKongressRuhr ist längst im radiologischen Veranstaltungskalender etabliert. Wir freuen uns, Sie nun schon im 8. Jahr zu einem exzellenten Fortbildungsprogramm einladen zu dürfen. Wir werden Ihnen auch 2015 weitere Neuerungen präsentieren, die den vielfältigen Fortbildungsaktivitäten unseres Faches Rechnung tragen:

- Hands-on Workshop Neurointerventionen

- Zertifizierungskurs DeGIR

- Workshop für Niedergelassene (Wirbelsäule/Neurochirurgie)

- Workshop Teleradiologie

- Q1/Q2-Kurse (MRT des Herzens)

- Fachkunde-Spezialkurs Computertomografie

- Fit-für-den-Facharzt (Onkologie)

- Programm für den radiologischen Nachwuchs (konventionelle Knochendiagnostik)

Der Hands-on-Workshop feiert in diesem Jahr Premiere. Er widmet sich 2015 den Neurointerventionen. Hier können Sie selbst Hand anlegen und an den Geräten ihre Fähigkeiten erweitern und spezialisieren. Neu ist auch der Fachkunde-Spezialkurs Computertomografie, der inzwischen für das Erlangen der CT-Fachkunde vorgeschrieben ist. Die Qualifizierungskurse der AG Herz- und Gefäßdiagnostik werden nach dem überwältigenden Erfolg in 2014 erneut in den Kategorien Q1-MRT des Herzens und Q2-MRT des Herzens angeboten. Der Freitag bleibt der Tag für die MTRA. Die VMTB hat ein hervorragendes Programm zusammengestellt und am Schülerdonnerstag ist auch der MTRANachwuchs herzlich willkommen, Kongressluft zu schnuppern.

Eingeladen sind selbstverständlich auch alle Medizinstudierenden, die kostenfrei am Kongress teilnehmen können. Das Programm für den radiologischen Nachwuchs behandelt in diesem Jahr das Thema der konventionellen Knochendiagnostik, welches auch für Medizinstudierende offensteht.

Wir freuen uns, Sie in Bochum begrüßen zu dürfen!

\section{Mit kollegialen Grüßen}

Prof. Dr. Gerald Antoch

Prof. Dr. Christiane Kuhl

Prof. Dr. Volkmar Nicolas 